\title{
Identifying patterns of cognitive deficits: the path to better outcomes after stroke
}

\author{
Stephanie Clarke
}

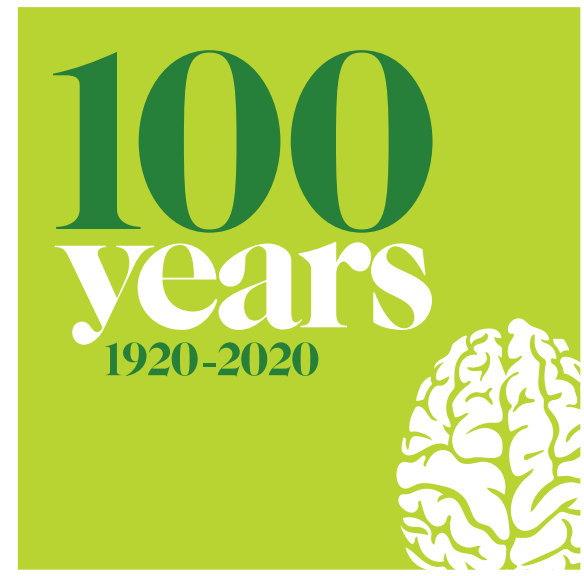

Today cognitive models are bound to impact on neurorehabilitation and define patient profiles, which respond to specific therapeutic interventions

The seminal paper by Tatemichi and colleagues $^{1}$ sets a cornerstone for the diagnosis of poststroke cognitive impairment. The authors documented the diversity of stroke-related cognitive deficits that were present 3 months after an ischaemic stroke. They used an extended neuropsychological battery, covering memory, orientation, language, visuospatial skills, abstract reasoning and attention and compared the performance of 227 patients with that of 240 control subjects. Cognitive impairment, defined as deficient performance in more than three domains, was found in $35.2 \%$ of stroke patients (vs in $3.8 \%$ of control subject) and involved mostly memory, orientation, language and attention. These deficits impacted on the ability to live independently.

Establishing the patterns of cognitive impairment after stroke was grounding for three lines of research. First, a series of studies documented the contribution of poststroke cognitive impairment to dementia. ${ }^{2}$ Second, the introduction of endovascular treatment improved the

Service de neuropsychologie et de neuroréhabilitation, Centre Hospitalier Universitaire Vaudois, Lausanne, Switzerland

Correspondence to Professor Stephanie Clarke, Service de neuropsychologie et de neuroréhabilitation, Centre Hospitalier Universitaire Vaudois, Lausanne 1011, Switzerland; stephanie.clarke@chuv.ch
Cognitive impairment after stroke: frequency, patterns, and relationship to functional abilities Authors: T K Tatemichi Year published: 1994 Number of times cited: 972

functional outcome of stroke patients, including the severity of cognitive syndromes. ${ }^{3}$ Third, innovative approaches in cognitive rehabilitation were shown to improve recovery during the postacute stage of stroke. ${ }^{4}$ The challenge which we face today is how to prevent the decline in dementia and how to create a continuum of care in which thrombolysis and/or thrombectomy during the acute stage is combined with appropriate cognitive rehabilitation during the later stages.

\section{POSTSTROKE DEMENTIA VERSUS NEUROPSYCHOLOGICAL SYNDROMES}

A meta-analysis of patient cohorts that were investigated from the late 1980 to early 2000 highlighted the causal role of stroke in dementia. The authors estimated that $10 \%$ of patients develop new dementia after a first stroke and $>30 \%$ after a recurring stroke. ${ }^{5}$ The incidence of new-onset poststroke dementia continues to rise during the following years. ${ }^{6}$ Dementia, which is diagnosed in the aftermath of stroke, is mostly associated with small-vessel occlusions and lacunar infarctions rather than large focal lesions. ${ }^{7}$

Large focal lesions tend to be associated with specific neuropsychological syndromes; the site of lesion tends to be typical of a syndrome, such as the infarction in the territory of the left middle cerebral artery in aphasia or of the right middle cerebral artery in unilateral neglect 4. Numerous studies investigated the neural basis of specific neuropsychological syndromes by testing subpopulations of patients who had a stroke with extended batteries of syndrome-specific tests. Concurring evidence from patient studies and from activation studies in normal subjects shows that a given neuropsychological syndrome comprises a range of functional features. These specific features can be impaired selectively, following lesions at critical locations, as demonstrated, for example, for different aspects of auditory verbal comprehension ${ }^{8}$ or for different types of auditory neglect. ${ }^{9}$

\section{THROMBOLYSIS AND THROMBECTOMY:} DECREASING THE SEVERITY OF NEUROPSYCHOLOGICAL SYNDROMES

Thrombolysis and/or thrombectomy are part of the integral management of patients who had a acute ischaemic stroke. ${ }^{10} 11$ Whereas early studies failed to show a positive effect of thrombolysis on the cognitive outcome, there is some evidence in later, more focused investigations, where intravenous thrombolysis was reported to be associated with less severe neuropsychological syndromes in patients who had a a first ischaemic stroke. ${ }^{3}$ In particular, this has been demonstrated for aphasia during the acute and postacute (3 months) stages of left middle cerebral artery infarction ${ }^{12}$ and for the severity of visuoperceptual dysfunction during the acute stage of right hemispheric infarction. ${ }^{13}$

\section{IMPACT OF COGNITIVE MODELS ON STROKE REHABILITATION}

Rehabilitation of cognitive functions has developed in parallel to motor rehabilitation. It comprises a wealth of specific approaches, many of which have used with some success in subpopulations of patients who had a stroke. ${ }^{4}$ Despite these encouraging reports, systematic reviews of randomised controlled trials tend to take, with few exceptions, a negative view. The positive effect has been attested for speech and language therapy. The authors of a seminal Cochrane Collaboration review conclude that speech and language therapy, as compared with no therapy, leads to the improvement of functional communication, reading, writing and expressive language. Furthermore, the therapy administered at high intensity, high dose or over a longer period may confer additional benefits. ${ }^{14}$ Other cognitive domains fare less well in systematic 
reviews. A Cochrane Collaboration reviewed evidence from randomised controlled trials for the effectiveness of cognitive rehabilitation in spatial neglect. The authors found that neglect rehabilitation interventions have a positive immediate effect on standardised neglect tests but do not influence the significantly long-term outcome as assessed in activities of daily living or standardised neglect tests. Furthermore, the authors deplored methodological weaknesses in over half of the studies, such as inadequate allocation concealment. They concluded that 'the effectiveness of cognitive rehabilitation intervention for reducing the disabling effects of neglect and increasing independence remains unproven'. 15

Apart from methodological drawbacks, such as inadequate concealment, which were pointed out in the Cochrane Collaboration review on neglect, ${ }^{15}$ cognitive rehabilitation suffers from conceptual problems, for which unilateral neglect offers a good illustration. ${ }^{16}$ Unilateral neglect is clinically very heterogeneous, affecting to a varying degree, visual, auditory, somatosensory and motor modalities. Even within the most often affected, visuospatial modality there are surprising dissociations between symptoms. Conversely, a whole range of therapeutic interventions is used in neglect rehabilitation, from topdown approaches, which aim at increasing the attentional load to the left side by behavioural training or TMS (transcranial magnetic stimulation) inactivation of the contralesional hemisphere, to bottom-up approaches which modulate sensorimotor integration. ${ }^{17}$ In clinical trials, the same therapeutic intervention is administered typically to all patients, independently of their neglect profiles. Evidence from recent studies indicates that a specific therapeutic intervention tends to be successful in a subgroup of neglect patients and that responders versus non-responders have different profiles, often with respect to the site of lesion. Neglect rehabilitation by means of prismatic adaptation is probably the most thoroughly investigated example of this. Unilateral neglect results from damage to the right-dominant ventral attentional system. ${ }^{18}$ Brief exposure to prismatic adaptation alleviates neglect symptoms ${ }^{19}$ by shifting the dominance of the ventral attentional system from the right to the left hemisphere. ${ }^{20}$ This model of neglect recovery predicts that only patients with preserved dorsal attentional system and preserved posterior callosal pathway will benefit from the shift in hemispheric dominance and hence respond to the treatment. This prediction has been validated in three independent studies. $^{21-23}$

Funding The authors have not declared a specific grant for this research from any funding agency in the public, commercial or not-for-profit sectors.

Competing interests None declared.

Patient consent for publication Not required.

Provenance and peer review Commissioned; internally peer reviewed.

(C) Author(s) (or their employer(s)) 2020. No commercial re-use. See rights and permissions. Published by BMJ.

\section{Check for updates}

To cite Clarke S. J Neurol Neurosurg Psychiatry 2020;91:449-450.

Received 3 February 2020

Accepted 19 February 2020

Published Online First 5 March 2020

J Neurol Neurosurg Psychiatry 2020;91:449-450. doi:10.1136/jnnp-2019-322429

\section{REFERENCES}

1 Tatemichi TK, Desmond DW, Stern Y, et al. Cognitive impairment after stroke: frequency, patterns, and relationship to functional abilities. J Neurol Neurosurg Psychiatry 1994;57:202-7.

2 Hachinski V, ladecola C, Petersen RC, et al. National Institute of neurological disorders and Stroke-Canadian stroke network vascular cognitive impairment harmonization standards. Stroke 2006;37:2220-41

3 Broome LJ, Battle CE, Lawrence M, et al. Cognitive outcomes following thrombolysis in acute ischemic stroke: a systematic review. J Stroke Cerebrovasc Dis 2016;25:2868-75

4 Cappa S, Benke T, Clarke S. Cognitive rehabilitation. In: Gilhus NE BM, Brainin M, eds. European Handbook of neurological management. 2nd edn. Oxfgord: WileyBlackwell, 2011: 545-67.

5 Pendlebury ST, Rothwell PM. Prevalence, incidence, and factors associated with pre-stroke and post-stroke dementia: a systematic review and meta-analysis. Lancet Neurol 2009;8:1006-18.

6 Leys D, Hénon H, Mackowiak-Cordoliani M-A, et al. Poststroke dementia. Lancet Neurol 2005;4:752-9.
7 Douiri A, Rudd AG, Wolfe CDA. Prevalence of poststroke cognitive impairment: South London stroke register 1995-2010. Stroke 2013;44:138-45.

8 Schneider L, Spierer L, Maeder P, et al. Auditory-verbal analysis in aphasia. Aphasiology 2016;30:1483-511.

9 Tissieres I, Crottaz-Herbette S, Clarke S. Exploring auditory neglect: Anatomo-clinical correlations of auditory extinction. Ann Phys Rehabil Med 2018;61:386-94.

10 Powers WJ, Derdeyn CP, Biller J, et al. 2015 American heart Association/American stroke association focused update of the 2013 guidelines for the early management of patients with acute ischemic stroke regarding endovascular treatment: a guideline for healthcare professionals from the American heart Association/American stroke association. Stroke 2015:46:3020-35.

11 Wahlgren N, Moreira T, Michel P, et al. Mechanical thrombectomy in acute ischemic stroke: consensus statement by ESO-Karolinska stroke update 2014/2015, supported by ESO, ESMINT, ESNR and EAN. Int J Stroke 2016;11:134-47.

12 Jacquin A, Virat-Brassaud M-E, Rouaud O, et al. Vascular aphasia outcome after intravenous recombinant tissue plasminogen activator thrombolysis for ischemic stroke. Eur Neurol 2014;71:288-95.

13 Laihosalo M, Kettunen JE, Koivisto A-M, et al. Thrombolytic therapy and visuoperceptual functions in right hemisphere infarct patients. J Neurol 2011;258:1021-5.

14 Brady MC, Kelly H, Godwin J, et al. Speech and language therapy for aphasia following stroke. Cochrane Database Syst Rev 2016;24:Cd000425

15 Bowen A, Hazelton C, Pollock A, et al. Cognitive rehabilitation for spatial neglect following stroke. Cochrane Database Syst Rev 2013;7:Cd003586.

16 Clarke S, Bindschaedler C, Crottaz-Herbette S. Impact of cognitive neuroscience on stroke rehabilitation. Stroke 2015;46:1408-13.

17 Clarke S, Bindschaedler C. Unilateral neglect and anosognosia. In: E. CS SM, Cohen LG, Kwakkel G, eds. Textbook of neural repair and rehabilitation. 2nd edn. Cambridge: Cambridge University Press, 2014: 463-77.

18 Corbetta M, Shulman GL. Spatial neglect and attention networks. Annu Rev Neurosci 2011;34:569-99.

19 Rossetti Y, Rode G, Pisella L, et al. Prism adaptation to a rightward optical deviation rehabilitates left hemispatial neglect. Nature 1998:395:166-9.

20 Clarke S, Crottaz-Herbette S. Modulation of visual attention by prismatic adaptation. Neuropsychologia 2016;92:31-41

21 Tissieres I, Elamly M, Clarke $\mathrm{S}$, et al. For better or worse: the effect of prismatic adaptation on auditory neglect. Neural Plast 2017;2017:1-11.

22 Goedert KM, Chen P, Foundas AL, et al. Frontal lesions predict response to prism adaptation treatment in spatial neglect: a randomised controlled study. Neuropsychol Rehabil 2020;30:32-53.

23 Gutierrez-Herrera M, Eger S, Keller I, et al. Neuroanatomical and behavioural factors associated with the effectiveness of two Weekly sessions of prism adaptation in the treatment of unilateral neglect. Neuropsychol Rehabil 2018:1-20. 